\title{
A PARTICIPAÇÃO POLÍTICA DOS ÍNDIOS: UMA TENTATIVA DE INCLUSÃO
}

Political Participation of Indians: an attempt to inclusion

Carolina Canhassi Pereira

Antônio Raimundo Barros de Carvalho Júnior

Resumo: A participação da comunidade indígena em postos eletivos é extremamente baixa, especialmente nos cargos públicos federais. O presente artigo traça linhas gerais acerca da subrepresentação política indígena e da possibilidade de considerar cotas eleitorais - discriminações positivas - para reserva de assentos no parlamento objetivando aumentar a defesa de sua cultura e tradições.

Palavras-chave: Indígena. Representação Política. Cotas Eleitorais. Assento Parlamento.

\begin{abstract}
The participation of the indigenous community in elective posts is extremely low, especially in federal public positions. This article outlines general lines about indigenous political underrepresentation and the possibility of considering electoral quotas - positive discrimination - to reserve seats in parliament in order to increase the defense of their culture and traditions.

Keywords: Indigenous. Political representation. Electoral quotas. Parliament seat.
\end{abstract}




\section{Introdução}

Este artigo tem como desafio a junção de dois temas pouco explorados pelo ordenamento jurídico brasileiro: o direito eleitoral, enquanto direito de participação na formação da vontade política do Estado, e os direitos dos povos indígenas. Uma tarefa difícil, que tem como escopo, a partir dessa conjugação, demonstrar como a participação na condução da vida política do país pode contribuir para que os direitos dessa minoria étnica não sejam esquecidos.

Como bem salientado por Lívia Nascimento Tinôco ${ }^{1}$, a invisibilidade das comunidades indígenas é um fenômeno estudado pela antropologia, pela sociologia e pelo direito. Curiosamente, os direitos indígenas somente ganham repercussão em meio a conflitos fundiários, quando contrapostos aos direitos da sociedade não indígena. Ocorrendo esse choque de interesses, percebe-se a carência de estudos e o quanto nosso conhecimento é limitado sobre o tema.

A relação dos povos indígenas com o território é especial, uma vez que a vida do índio depende essencialmente do espaço que ocupa: as relações econômicas, sociais, as manifestações culturais e religiosas e a constituição familiar são resultados da interação com a terra. Não há sobrevivência do indígena sem a terra.

É por essa razão que, quase sempre, os direitos indígenas ganham destaque por ocasião da disputa territorial, especialmente em contraposição com direitos dos não índios.

O julgamento do caso da demarcação da terra indígena denominada Raposa da Serra do Sol ${ }^{2}$ pelo Supremo Tribunal Federal (STF) é um exemplo paradigmático dessa sistemática contextual: os direitos dos indígenas mereceram atenção porque foram confrontados com os dos não indígenas, no caso, fazendeiros e políticos contrários à demarcação.

Esse julgamento representou um marco de reavaliação na política indigenista brasileira e mostrou a dificuldade de construção de uma socie-

\footnotetext{
${ }^{1}$ SANTANA, Carolina R. Direitos territoriais indígenas: o STF contra a Constituição. In: ALCÂNTARA, Gustavo Kenner; MAIA, Luciano Maris; TINÔCO, Lívia N. (Org.). Índios, direitos originários e territorialidade. Brasília: Editora ANPR, 2018.

${ }^{2}$ Petição no 3.388 em Ação Popular, garantiu aos povos indígenas Ingaricó, Macuxi, Pantamona, Taurepangue e Uapixana o reconhecimento de suas terras, respeitando-se a tradição jurídica do reconhecimento dos territórios indígenas e da não aceitação do esbulho como forma de aquisição de propriedade.
} 
dade democrática, que respeita a diversidade a partir dos direitos humanos dos índios.

O objetivo deste artigo é explorar o direito do indígena em contexto apartado ao da disputa de terra e desvencilhar da ligação normalmente existente entre a abordagem do direito do índio com a do não-índio. Busca-se aqui o direito em sua forma primária.

Com isso, pretende-se demonstrar que a visibilidade dos povos indígenas pode ser ampliada por meio do exercício de um direito fundamental expresso na Constituição Federal: o direito de participação política.

Os direitos políticos são direitos fundamentais que viabilizam a existência da democracia e proporcionam o pleno desenvolvimento humano. A participação das minorias na condução da vida política do Estado é fundamental para a construção de uma sociedade verdadeiramente diversa, pluralista e democrática.

Observa-se, no cenário brasileiro, a participação ativa do indígena por meio do voto, todavia, nem sempre alinhada aos interesses da comunidade. $\mathrm{O}$ índio elege o representante muitas vezes não comprometido com as demandas indígenas. A participação na elaboração das políticas indigenistas tem se mostrado insatisfatória e a elegibilidade desta minoria étnica é inexpressiva, conforme dados obtidos no sítio do Tribunal Superior Eleitoral ${ }^{3}$.

$\mathrm{O}$ artigo 231, $\int 3^{\circ}$ da Constituição Federal $^{4}$ e o artigo $2^{\circ}$ do desatualizado Estatuto do Índio preveem ser direito das comunidades indígenas a participação nas decisões do Estado, garantindo procedimentos adequados de consulta, por meio de instituições representativas sobre políticas e ações governamentais que lhes afetem.

A participação dos índios como representantes legislativos em contexto ordenador da política nacional e o consentimento dos povos indígenas nas ações de políticas públicas implicam em decisões com maior consenso e, portanto, com mais legitimidade.

\footnotetext{
${ }^{3}$ Segundo o Tribunal Superior Eleitoral, no ano de 2014, de todas as candidaturas deferidas para os cargos de Deputado Estadual, Deputado Federal, Senador, Governador, Vice-Governador, Presidente e Vice-Presidente apenas 74 dos candidatos declararam-se índios, o que representou 0,34\% do total de candidaturas. Em 2018, houve um pequeno aumento, para os mesmos cargos; 121 dos candidatos se auto declararam índios, representando $0,47 \%$ do total.

${ }^{4}$ No mesmo sentido, o artigo $6^{\circ}$ da Convenção da Organização Internacional do Trabalho.
} 
Dessa forma, o grande desafio é: como introduzi-los no cenário político brasileiro? Como ampliar a representatividade política dos grupos indígenas?

As condições para o exercício do direito ao sufrágio pelos índios é um tema a ser estudado: abordar questões como a obrigatoriedade de comprovação de quitação do serviço militar ou da prestação alternativa como requisito para o alistamento eleitoral; o domicílio eleitoral dos índios nômades; a obrigatoriedade da propaganda eleitoral ser realizada no idioma nacional; o domínio da língua portuguesa como requisito de elegibilidade e a compra e venda de votos na comunidade indígena são de fundamental importância.

Não será possível o estudo de todos esses temas neste artigo, mas registra-se a necessidade de estudo pelos pesquisadores do assunto.

Por vezes, a própria interpretação e alcance da norma acabam por criar entraves ao exercício do direito. A participação política não é plena, os direitos políticos são adquiridos de forma gradual e o seu exercício é condicionado ao preenchimento de condições especiais. Todavia, essas restrições ${ }^{5}$ não podem ser interpretadas ao ponto de obstaculizar o próprio direito.

A exemplo de outros países da América Latina, como Colômbia, Venezuela, Chile e México, a reserva de assentos no parlamento a essa minoria étnica é uma realidade.

No Brasil, houve a Proposta de Emenda Constitucional $\mathrm{n}^{\circ}$ 320/2013, de autoria do deputado Nilmário Miranda (PT-MG), sugerindo a criação de 04 (quatro) vagas especiais para deputados federais a serem ocupadas por indígenas, como tentativa de romper a falta de representatividade indígena.

Esses tópicos serão abordados no decorrer deste trabalho.

\footnotetext{
${ }^{5} \mathrm{O}$ artigo 25 do Pacto Internacional de Direitos Civis e Políticos veda restrições infundadas à aquisição dos direitos políticos. $\mathrm{O}$ artigo 23 da Convenção Interamericana enumera de forma taxativa os parâmetros para que a lei regule o exercício dos direitos políticos: idade, nacionalidade, residência, idioma, instrução, capacidade civil ou mental, ou condenação por juiz competente em processo penal.
} 


\section{Breves considerações sobre a legislação indígena no Brasil}

Historicamente, a perspectiva do Estado brasileiro a respeito das diferenças culturais dos povos indígenas era no sentido de eliminá-las, objetivando integrá-las a uma cultura considerada dominante, a da comunidade nacional. Esse pensamento contribuiu para a extinção de boa parte da cultura tradicional dos povos originários do Brasil.

O Estatuto do Índio (Lei no 6.001/1973) foi o primeiro documento legal a tratar de maneira específica sobre os direitos dos índios e representa a política integracionista, cuja finalidade é assimilá-los à sociedade brasileira, fazendo-os abandonar gradativamente suas características tradicionais.

Gersem dos Santos Luciano ${ }^{6}$ (2006), antropólogo e indígena, da etnia Baniwa, esclarece que os povos indígenas foram obrigados, por meio de repressão física e cultural, a reprimir e negar suas culturas e identidades como forma de sobrevivência diante da sociedade colonial. Não havia escolha para os índios, ou eram exterminados fisicamente ou extintos pelo processo de integração e assimilação.

A Constituição Federal de 1988 alterou substancialmente esse panorama, passando a reconhecer e proteger, de forma expressa, as diferenças culturais dos povos indígenas. A proteção passa a ser integral, do indivíduo e da coletividade, legitimando a organização social, política, cultural e religiosa de acordo com os costumes e as tradições indígenas, além do reconhecimento do direito originário sobre as terras tradicionalmente ocupadas.

Os índios foram reconhecidos como membros de coletividades culturalmente diferenciadas e titulares de direitos especiais. No plano normativo, o paradigma da assimilação está superado, rompendo-se por com-

\footnotetext{
${ }^{6}$ LUCIANO. Gersem dos Santos: O Índio Brasileiro: o que você precisa saber sobre os povos indígenas no Brasil de hoje. Brasília: MEC/SECAD; LACED/Museu Nacional, 2006. 233p. (Coleção Educação Para Todos. Série Vias dos Saberes n. 1). Disponível em: <http://www.educadores.diaadia.pr.gov.br/arquivos/File/pdf/indio_brasileiro.pdf >. Acesso em: 05 maio 2020. Gersem José dos Santos Luciano é doutor em Antropologia Social pela Universidade de Brasília (UnB), de etnia Baniwa, nascido na aldeia Yaquirana, no Alto Rio Negro, Amazonas. Professor indígena, integrou o Conselho Nacional de Educação (CNE) e esteve à frente da Coordenação da Educação Escolar Indígena, no Ministério da Educação (Secad/MEC).
} 
pleto com a ideologia integracionista do desatualizado Estatuto do Índio, conforme afirma Gersem dos Santos Luciano - Baniwa ${ }^{7}$, in verbis:

A conquista histórica dos direitos na Constituição promulgada em 1988 mudou substancialmente o destino dos povos indígenas do Brasil. De transitórios e incapazes passaram a protagonistas, sujeitos coletivos e sujeitos de direitos e de cidadania brasileira e planetária (LUCIANO, 2006).

Logo, deixou de ser atribuição do Estado legislar sobre a integração dos povos indígenas à comunhão nacional, cabendo-lhe o dever de garantir o direito à diferença, impondo-se a total inversão de suas ações, historicamente orientadas à assimilação.

\section{O regime jurídico especial de proteção ao índio e o direito de participação política}

A Constituição Federal, no artigo 231, estabelece regime especial de proteção por meio do qual são reconhecidos a organização social, os costumes, as línguas, as crenças e tradições ${ }^{8}$ dos povos indígenas. O caput tem como fundamento o princípio da igualdade. Os povos indígenas são iguais aos demais povos e, ao mesmo tempo, possuem o direito de serem reconhecidos em suas diferenças.

Qualquer limitação desrespeitando a diversidade, os valores culturais e a identidade étnica do povo indígena implica em violação a seus direitos e liberdades fundamentais.

A Declaração das Nações Unidas sobre o Direito dos Povos Indígenas ${ }^{9}$ reconhece o gozo desses direitos na condição de coletividades diferenciadas e autônomas. Todo o documento é marcado pela autodetermi-

\footnotetext{
${ }^{7}$ LUCIANO. Gersem dos Santos: O Índio Brasileiro: o que você precisa saber sobre os povos indígenas no Brasil de hoje. Brasília: MEC/SECAD; LACED/Museu Nacional, 2006. 233p. (Coleção Educação Para Todos. Série Vias dos Saberes n. 1). Disponível em: <http://www.educadores.diaadia. pr.gov.br/arquivos /File/pdf/indio_brasileiro.pdf $>$. Acesso em: 05 maio 2020

${ }^{8}$ Segundo dados do Censo Demográfico realizado pelo IBGE em 2010, são 817 mil indígenas espalhados em todos os estados da federação e Distrito Federal. Um grupo heterogêneo composto de 225 etnias e falante de 180 línguas diferentes. A Funai registra 69 referências de índios ainda não contatados.
}

${ }^{9}$ Aprovada em 07 de setembro de 2007 pela Assembleia Geral das Nações Unidas. 
nação ${ }^{10}$, em contraposição a limitações impostas por formas de dominação política, cultural e territorial. As diferentes etnias da população indígena possuem o direito de determinar livremente sua condição política e buscar dessa forma seu desenvolvimento social, econômico e cultural.

Como extensão da autodeterminação, os indígenas têm direito à autonomia e ao autogoverno nas questões relacionadas a assuntos internos e locais. $\mathrm{O}$ artigo 5o da Declaração de Direitos dos Povos Indígenas prevê, de forma expressa, o direito de conservar e reforçar as instituições políticas, jurídicas, econômicas, sociais e culturais, mantendo o direito de participar plenamente, se assim desejarem, da vida em sociedade.

Diz o artigo $3^{\circ}$ que os povos indígenas têm direito à autodeterminação. Em virtude desse direito, determinam livremente sua condição política e buscam, com a mesma liberdade, seu desenvolvimento econômico, social e cultural.

No artigo 4º, os povos indígenas, no exercício do seu direito à autodeterminação, têm direito também à autonomia ou ao autogoverno nas questões relacionadas a seus assuntos internos e locais, assim como a disporem dos meios para financiar suas funções autônomas.

O artigo $1^{\varrho}$, do Pacto Internacional de Direitos Civis e Políticos de 1966 determina que: "Todos os povos têm direito à autodeterminação. Em virtude desse direito, determinam livremente seu estatuto político e asseguram livremente seu desenvolvimento econômico, social e cultural."

O artigo $6^{\circ}$ da Convenção n⿳o 169 sobre Povos Indígenas e Tribais da Organização Internacional do Trabalho é outro documento internacional que determina aos governos ratificadores, o dever de criação de instrumentos pelos quais a comunidade indígena possa participar livremente da sociedade, ou, pelo menos, na mesma medida assegurada aos demais cidadãos, e de garantir a participação em todos os níveis decisórios de instituições eletivas ou órgãos administrativos responsáveis por políticas e programas de governo.

\footnotetext{
${ }^{10}$ Artigo 30: Os povos indígenas têm direito à autodeterminação. Em virtude desse direito determinam livremente sua condição política e buscam livremente seu desenvolvimento econômico, social e cultural. Artigo 4웅 Os povos indígenas, no exercício do seu direito à autodeterminação, têm direito à autonomia ou ao autogoverno nas questões relacionadas a seus assuntos internos e locais, assim como a disporem dos meios para financiar suas funções autônomas. O artigo 1ํㅜㅇ do Pacto Internacional de Direitos Civis e Políticos de 1966: "Todos os povos têm direito à autodeterminação. Em virtude desse direito, determinam livremente seu estatuto político e asseguram livremente seu desenvolvimento econômico, social e cultural"
} 
O exercício da autodeterminação implica na capacidade de deliberar e decidir sobre assuntos de seu interesse sem submissão aos grupos majoritários. Daí a importância de instituições representativas nos âmbitos social, econômico, jurídico, cultural e, sobretudo, da participação política dos povos indígenas. A autodeterminação pode ser interpretada como garantia à plena participação em regime democrático, permitindo a grupos minoritários a atuação efetiva em processos políticos que afetem suas vidas (ANJOS FILHO, 2013).

Nesse viés, o exercício dos direitos políticos por parte dos grupos indígenas representa extensão do direito da autodeterminação. Os direitos políticos enquanto direitos fundamentais viabilizam e promovem o exercício de outros direitos.

O fundamento é a dignidade humana, cujo elemento ético é a autonomia ${ }^{11}$. A vontade livre de buscar e escolher a melhor forma de viver. Essa liberdade de escolha, núcleo da autonomia, abrange decisões pessoais, sociais, culturais, religiosas e políticas.

As escolhas políticas reverberam no meio social diferentemente da autonomia privada ${ }^{12}$. O direito à participação política direta ou indireta (autonomia pública) é uma manifestação do autogoverno (autodeterminação) que implica nos direitos de votar, ser eleito, concorrer a cargos públicos, participar de debates públicos, fazer parte de movimentos sociais, entre outros.

A Declaração Universal dos Direitos do Homem de 1948 reconhece a todos os seres humanos o direito de participar da direção dos assuntos políticos do Estado e na formação das leis, seja de forma direta ou indireta. Todos os cidadãos têm o direito de concorrer, pessoalmente ou por meio de mandatários, para a sua formação.

O Pacto Internacional dos Direitos Civis e Políticos declarou que todo cidadão tem o direito de participar da condução dos assuntos públicos, diretamente ou por meio de representantes livremente escolhidos, de votar e de ser eleito em eleições periódicas e de ter acesso, em condições de igualdade, às funções públicas de seu país.

${ }^{11}$ BARROSO, Luís Roberto. Aqui, lá e em todo lugar: a dignidade humana no direito contemporâneo e no discurso transnacional. Trad. Humberto Laport de Mello. Revista dos Tribunais, São Paulo, v. 101, n. 919, p. 127-196, maio 2012.

${ }^{12}$ HABERMAS, Jürgen. Between Facts and Norms: Contributions to a Discourse Theory of Law and Democracy, 1996. p.86-104. 
Os direitos políticos viabilizam a existência da democracia e figuram, ao lado de outros direitos, como condição para o pleno desenvolvimento humano. São condições de existência de uma sociedade diversa e pluralista, pelo fato de garantir ao cidadão o direito de ser ouvido e de subordinar o funcionamento do Estado à vontade da comunidade.

Dessa forma, a participação política e a autodeterminação dos povos indígenas são duas faces da mesma moeda.

\section{As limitações ao exercício dos direitos políticos dos índios}

Os direitos políticos são adquiridos de forma gradual e o seu exercício depende do preenchimento de requisitos especiais expressos no texto constitucional.

Essas restrições estão previstas no artigo 14 e fazem parte do núcleo intangível da Constituição Federal. São limites ao poder reformador. Dessa forma, não é possível que outras limitações sejam criadas além daquelas já previstas expressamente no texto constitucional. Os direitos políticos são cláusulas pétreas, de modo que a única alteração admissível em matéria de reforma é a ampliação do âmbito de proteção dos direitos que essas cláusulas visam proteger ${ }^{13}$, jamais a redução (SAMPAIO, p. 95) .

$\mathrm{O}$ artigo 23 da Convenção Interamericana de Direitos Humanos enumera de forma taxativa os parâmetros para a regulação do exercício dos direitos políticos: idade, nacionalidade, residência, idioma, instrução, capacidade civil ou mental, ou condenação por juiz competente em processo penal. O artigo 25 do Pacto Internacional de Direitos Civis e Políticos veda restrições infundadas à aquisição dos direitos políticos.

Mônica Herman Caggiano ${ }^{14}$ pontua que as restrições à candidatura e ao exercício dos direitos políticos dos cidadãos devem ser somente as absolutamente necessárias, devendo ser rechaçadas as medidas exageradamente impeditivas.

\footnotetext{
${ }^{13}$ Para Nelson de Sousa Sampaio, a reforma constitucional pode ampliar, como também pode a lei ordinária, os direitos fundamentais, mas nunca os restringir e, muito menos, abolir. SAMPAIO, Nelson de Sousa. O Poder de Reforma Constitucional. Bahia: Livraria Progresso Editora, 1954. p. 95.

${ }^{14}$ CAGGIANO, Mônica Herman S. Sistemas eleitorais x representação política. São Paulo, 1987. p. 72.
} 
A interpretação e o alcance das restrições estabelecidas pelo texto constitucional, por vezes, podem obstaculizar o exercício dos direitos políticos pela comunidade indígena.

Há situações práticas nas quais a interpretação da norma cria entraves que inviabilizam a cidadania dessa minoria étnica. Não é objetivo de este artigo abordar todas elas, mas trazer alguns exemplos com a finalidade de adequá-los ao espírito da Constituição Federal.

O alistamento eleitoral é um deles. A Constituição Federal estabelece que o alistamento, assim como o voto, é obrigatório para os maiores de 18 anos; facultativo para os maiores de 16 anos, maiores de 70 anos e analfabetos, e vedado aos estrangeiros e conscritos.

O alistamento é ato jurídico por meio do qual a pessoa natural passa a fazer parte do cadastro de eleitores da Justiça Eleitoral. É um ato formal habilitando o indivíduo a participar do processo político por meio do voto (capacidade ativa).

O artigo 44, II do Código Eleitoral impõe como requisito ao alistamento eleitoral dos brasileiros do sexo masculino, entre 18 (dezoito) e 45 (quarenta e cinco) anos, a comprovação da quitação do serviço militar ou da prestação alternativa em caso de recusa.

A obrigatoriedade do alistamento eleitoral do índio foi ementada pelo Tribunal Superior Eleitoral na Resolução n⿳丷ㅡㄹ 20.806, de 15 de maio de $2001^{15}$.

O Tribunal baseou-se no desatualizado Estatuto do Índio (Lei 6.001/73) para diferenciar o índio "integrado" do "não integrado", designações não recepcionadas pela Constituição Federal. No primeiro caso, quando maiores de 18 anos e alfabetizados, o alistamento eleitoral dependeria da comprovação da quitação do serviço militar ou do cumprimento da prestação alternativa. Nos demais casos, poderiam optar pelo registro de nascimento emitido pela FUNAI.

Posteriormente, o Tribunal Superior Eleitoral reviu seu posicionamento no bojo do Processo Administrativo no 1919-30.2014.6.00.0000,

15 “ALISTAMENTO ELEITORAL. EXIGÊNCIAS. São aplicáveis aos indígenas integrados, reconhecidos no pleno exercício dos direitos civis, nos termos da legislação especial (Estatuto do Índio), as exigências impostas para o alistamento eleitoral, inclusive de comprovação de quitação do serviço militar ou de cumprimento de prestação alternativa" (Processo Administrativo no 18391 - Macapá/AP, Rel. Min. Jacy Garcia Vieira, Diário de Justiça, v. 1, 24 ago. 2001, p. 173). 
de relatoria do ministro João Otávio de Noronha, no qual a Procuradoria Regional Eleitoral do estado de São Paulo requereu a dispensa de apresentação de certificado de quitação do serviço militar quando do alistamento do indígena, de forma a resguardar o direito à organização social e à preservação de seus costumes, crenças e tradições, bem como garantir-lhe o exercício da cidadania ${ }^{16}$.

O Tribunal abandonou a categorização trazida pelo Estatuto do Índio, que os diferenciava em integrados e não integrados, contudo, manteve a exigência de comprovação da quitação do serviço militar (ou dispensa) ${ }^{17}$ ou da prestação alternativa para o alistamento eleitoral.

Com a devida vênia a esse posicionamento, embora o serviço militar seja obrigatório no Brasil, essa exigência para o alistamento eleitoral dos indígenas não encontra respaldo na Constituição da República. Além de contrariar o caput do artigo 231, que protege a cultura, os costumes e

${ }^{16}$ PROCESSO ADMINISTRATIVO. SOLICITAÇÃO. ALTERAÇÃO. NORMAS DE SERVIÇO. EXIGÊNCIA. APRESENTAÇÃO. COMPROVANTE. QUITAÇÃO MILITAR. INDÍGENAS "INTEGRADOS”. GARANTIA. ALISTAMENTO ELEITORAL. DESINFLUÊNCIA. CATEGORIZAÇÃO. ATENDIMENTO. PRECEITOS LEGAIS. APRESENTAÇÃO. DOCUMENTAÇÃO COMPROBATÓRIA.

1. Os indígenas têm assegurado o direito de se alistar como eleitores e de votar, independentemente de categorização prevista em legislação especial infraconstitucional, a partir dos dezesseis anos, desde que atendidos os preceitos legais regulamentadores da matéria, conforme orientação firmada por esta Corte Superior.

2. Todo cidadão do sexo masculino, maior de dezoito anos, que comparece a unidade eleitoral - cartório, posto ou central de atendimento - com a finalidade de se alistar eleitor, deve apresentar, entre outros documentos, comprovante de quitação das obrigações militares, nos exatos termos do art. 44, II, do Código Eleitoral.

3. Tendo em conta a desinfluência da classificação conferida ao indígena para esta Justiça especializada e a garantia constitucional relativamente a sua organização social, costumes, línguas, crenças e tradições (Constituição, art. 231), será solicitado, na hipótese de requerer alistamento eleitoral, documento hábil obtido na unidade do serviço militar do qual se infira sua regularidade com as obrigações correspondentes, seja pela prestação, dispensa, isenção ou quaisquer outros motivos admitidos pela legislação de regência da matéria, em conjunto ou não com o do órgão competente de assistência que comprove a condição de indígena, ambos estranhos à órbita de atuação da Justiça Eleitoral.

${ }^{17}$ O Ministério da Defesa editou a Portaria no 983 objetivando estabelecer diretrizes para o relacionamento das forças armadas nas comunidades indígenas. Com relação ao serviço militar, o órgão federal passou a facultar aos indígenas a prestação "quando da seleção para o serviço militar inicial, dependendo da localidade onde se der o recrutamento, a priorização da incorporação de jovens oriundos das comunidades indígenas, desde que voluntários e aprovados no processo de seleção".

Resenha Eleitoral (Florianópolis), v. 24, n. 2, p. 139-162, 2020 
as crenças, essa imposição legal cria restrição ao exercício da cidadania ao exigir obrigações estranhas às tradições indígenas.

Como anteriormente mencionado, a lei não pode ampliar as restrições previstas no texto constitucional e, com isso, impedir o exercício da cidadania indígena. A condição não encontra respaldo no artigo 14 da Constituição Federal e tampouco adequa-se ao regime jurídico especial de reconhecimento da diversidade e autodeterminação indígena. Portanto, a exigência de apresentação do comprovante do serviço militar ou da prestação alternativa para o alistamento eleitoral do índio é inconstitucional.

Outro ponto relevante com reflexo direto na participação política dos indígenas diz respeito ao uso da língua nativa nas propagandas eleitorais. O Código Eleitoral prevê expressamente a obrigatoriedade do uso da língua portuguesa ${ }^{18}$. A propaganda eleitoral tem por finalidade divulgar as propostas a serem defendidas pelos diferentes candidatos e partidos políticos, por meio de mensagens dirigidas aos eleitores, objetivando convencê-los à escolha dos representantes no dia do pleito.

É importante que a propaganda eleitoral atinja as comunidades indígenas em todo o território nacional, incluindo as mais distantes. O Brasil possui cerca de 800.000 (oitocentos mil) índios, segundo pesquisa censitária realizada pelo Instituto Brasileiro de Geografia e Estatística (IBGE), em 2010. São aproximadamente 180 (cento e oitenta) línguas faladas.

Não se pode perder de vista que a diversidade étnica é uma característica brasileira consagrada na Constituição Federal. A participação política desses diferentes grupos depende do acesso aos institutos do direito eleitoral, como a propaganda na língua materna. A Constituição Federal consagra, também, o direito à identidade dos grupos indígenas ${ }^{19}$, por meio do reconhecimento da cultura e da língua própria. Desse modo, há neces-

\footnotetext{
${ }^{18}$ Art.242: A propaganda, qualquer que seja a sua forma ou modalidade, mencionará sempre a legenda partidária e só poderá ser feita em língua nacional, não devendo empregar meios publicitários destinados a criar, artificialmente, na opinião pública, estados mentais, emocionais ou passionais. (Redação dada pela Lei no 7.476, de 15.5.1986). Art.355: fazer propaganda, qualquer que seja a sua forma, em língua estrangeira: Pena - detenção de três a seis meses e pagamento de 30 a 60 dias-multa. Parágrafo único. Além da pena cominada, a infração ao presente artigo importa na apreensão e perda do material utilizado na propaganda.

${ }^{19} \mathrm{O}$ multiculturalismo consiste no respeito pela diversidade étnica, religiosa e cultural. As minorias têm direito às suas identidades e diferenças, assim como o direito de serem reconhecidas.
} 
sidade de veiculação de propaganda e informativos com conteúdo eleitoral nas línguas dos povos tradicionais.

O Tribunal Regional Eleitoral do Tocantins ${ }^{20}$, no ano de 2017, pretendendo maior inclusão das comunidades indígenas locais, promoveu a confecção de cartilhas bilíngues, com informações sobre o processo eleitoral, o voto consciente e os crimes eleitorais, traduzidas em 4 (quatro) diferentes línguas indígenas no Estado, pertencentes às etnias Kraô, Xerente, Karajá e Apinajé.

Essa iniciativa merece destaque e serve de exemplo para os demais Tribunais Regionais Eleitorais.

\section{A elegilidade indígena}

Assim como os demais cidadãos, a elegibilidade indígena depende do preenchimento das condições previstas no artigo 14, \ $3^{\circ}$ da Constituição da República e, aliado à ausência de causa de inelegibilidades ${ }^{21}$, o índio terá o direito de candidatar-se a cargos políticos.

As condições de elegibilidade são: nacionalidade brasileira, filiação partidária, domicílio eleitoral na circunscrição onde disputará o cargo eletivo, idade mínima (variável conforme o cargo a ser disputado) e o pleno gozo dos direitos políticos. São inelegíveis os analfabetos, os estrangeiros e os conscritos.

A elegibilidade do índio brasileiro é inexpressiva. Segundo dados do Superior Tribunal Eleitoral22 ${ }^{22}$, no ano de 2014, de todas as candidaturas deferidas para os cargos de Deputado Estadual, Deputado Federal, Senador, Governador, Vice-Governador, Presidente e Vice-Presidente apenas 74 dos candidatos declararam-se índios, o que representou $0,34 \%$ do total de candidaturas. Em 2018, houve um pequeno aumento, para os mesmos cargos, e 121 dos candidatos se auto declararam índios, representando $0,47 \%$ do total.

${ }^{20}$ Disponível em: <http://www.tre-to.jus.br/imprensa/noticias-tre-to/2018/Setembro/ tre-to-lanca-cartilhas-bilingues-e-traduz-informacoes-eleitorais-para-linguas-indigenas-do-tocantins>. Acesso em :04 maio 2020.

${ }^{21}$ As causas de inelegibilidade estão previstas no artigo 14 , $\iint 4^{\circ}$ a $7^{\circ}$ e, também, na Lei Complementar no 64/90.

${ }^{22}$ Disponível em: < http://www.tse.jus.br/imprensa/noticias-tse/2019/Abril/candidatos-indigenas-aumentam-participacao-em-eleicoes-nacionais>. Acesso em: 27 abr. 2020.

Resenha Eleitoral (Florianópolis), v. 24, n. 2, p. 139-162, 2020 
A filiação partidária é uma das causas de elegibilidade. $\mathrm{O}$ índio necessita estar filiado a uma agremiação partidária para concorrer ao pleito. Contudo, no Brasil, não existe nenhuma ação afirmativa obrigando os partidos políticos a reservarem um percentual de vagas ou assentos para candidatos indígenas.

O domínio da língua portuguesa também pode ser obstáculo para a elegibilidade do indígena, uma vez que ser alfabetizado no idioma oficial nacional é condição da capacidade eleitoral passiva. Há entendimento que não considera a alfabetização na língua indígena para efeito do preenchimento dessa condição. De acordo com esse posicionamento, o índio deve dominar as técnicas de escrita e leitura na língua portuguesa, mesmo sendo alfabetizado na língua materna.

Essa compreensão não se adequa aos preceitos constitucionais, porquanto, abandonou-se a ideia de integração do índio à comunhão nacional, reconhecendo o direito à diversidade cultural das minorias étnicas. As línguas indígenas das diversas etnias são oficialmente protegidas pela Constituição Federal.

Nessa direção, merece destaque a decisão colegiada proferida pelo Tribunal Regional do Mato Grosso no Recurso Eleitoral no 270/2008 Acórdão $\mathrm{n}^{\mathrm{o}} 17.487^{23}$ - reformando a sentença do juiz eleitoral que indeferiu a candidatura de um indígena por considerá-lo não alfabetizado no idioma nacional. Embora o Tribunal Regional Eleitoral do Mato Grosso tenha utilizado designação considerada inconstitucional ("aculturado"), foi louvável o entendimento firmado, permitindo a elegibilidade do índio alfabetizado apenas na língua de sua etnia.

No Brasil, existem 5.570 (cinco mil quinhentos e setenta) municípios e, em respeito à identidade indígena, o Tribunal Superior Eleitoral, pela primeira vez, identificou as etnias e os candidatos índios nas eleições para a Chefia do Poder Executivo Municipal do ano de 2016, ocasião em que foram eleitos 04 (quatro) prefeitos indígenas no Brasil. São eles: Isaac Piyãko, da etnia Ashaninka, eleito em Marechal Thaumaturgo, no Acre,

\footnotetext{
${ }^{23}$ RECURSO ELEITORAL. REGISTRO DE CANDIDATURA. INDEFERIMENTO. TESTE DE ALFABETIZAÇÃO INDÍGENA ACULTURADO. ALFABETIZAÇÃO POR SUA ETNIA. POSSIBILIDADE. PECULIARIDADES - INELEGIBILIDADE AFASTADA - RECURSO PROVIDO - SENTENÇA REFORMADA. Tratando-se de indígena aculturado e alfabetizado por sua etnia, não incide a causa de inelegibilidade prevista no art. 14 , parágrafo $4^{\circ}$, da Constituição Federal.
} 
cidade com aproximadamente 16.000 (dezesseis mil) habitantes dos quais 1.200 (mil e duzentos) identificam-se como indígenas; Clóvis Saldanha, da etnia Tariano, eleito em São Gabriel da Cachoeira, no Amazonas, município com população em torno de 45.000 (quarenta e cinco mil) habitantes, sendo que $90 \%$ (noventa por cento) deles são indígenas, a maior do país; Rossine Blesmany dos Santos Cordeiro, da etnia Xukuru, reeleita na cidade pernambucana de Lajedo, com população em torno de 40.000 (quarenta mil) habitantes; e Eliselma Pereira, da etnia Potiguara, eleita na cidade de Marcação, na Paraíba, com população estimada em 7.000 (sete mil) habitantes dos quais $77 \%$ (setenta e sete por cento) identificam-se como indígenas da etnia Potiguar.

Em toda a história de existência do Legislativo federal, o Brasil teve apenas 02 (dois) deputados federais de origem indígena. O primeiro deles foi Mário Juruna, da etnia Xavante, eleito pelo estado do Rio de Janeiro em 1983. Após 37 (trinta e sete) anos, Joênia Batista de Carvalho, conhecida como Joênia Wapichana, da etnia Wapichana, foi eleita pelo estado de Roraima em 2018. Um dado interessante é que Joênia foi a primeira advogada indígena a realizar uma sustentação oral no Supremo Tribunal Federal, por ocasião do julgamento do caso da demarcação da terra indígena Raposa Serra do Sol (Petição 3388/RR).

Esses dados demonstram a sub-representação dos povos indígenas e a necessidade da adoção de ações afirmativas voltadas a ampliar a participação política do índio.

\section{As cotas eleitorais indígenas: uma proposta de inclusão}

A discriminação e o preconceito racial são fatores que contribuem para a invisibilidade da comunidade indígena. Para adentrar ao tema, é necessário partir da premissa de que o preconceito racial existe no Brasil e é uma das principais causas impeditivas da ascensão política e socioeconômica de grupos vulneráveis. Infelizmente, o índio brasileiro ainda representa o estranho, o selvagem, o nu, com adorno e pintura corporais.

Segundo dados não tão recentes do Instituto de Pesquisa Econômica Aplicada a partir da Pesquisa Nacional por Amostra de Domicílio (PNAD/IBGE) ${ }^{24}$, os índios representavam $0,2 \%$ da população brasileira

${ }^{24}$ Dados extraídos do IPEA, "Desigualdades Raciais do Brasil". 
em 1999. Desse percentual, a totalidade vivia em situação de pobreza, com um número considerável de indivíduos em situação de rua.

A Convenção da Organização das Nações Unidas sobre a eliminação de todas as formas de Discriminação Racial ${ }^{25}$, definiu a discriminação no artigo $1^{\circ}$ como "qualquer distinção, exclusão, restrição ou preferência baseada em raça, cor, descendência ou origem nacional ou étnica, que tenha o propósito ou o efeito de anular ou prejudicar o reconhecimento, gozo ou exercício em pé de igualdade dos direitos humanos e liberdades fundamentais."

Os atos discriminatórios estão baseados na raça ${ }^{26}$ e tem como propósito ou efeito restringir o exercício de direitos, nas esferas pública e privada. Como consequência, o Estado tem o dever de prevenir, proibir e punir a discriminação racial e de adotar ações afirmativas voltadas a promover a igualdade.

As ações afirmativas são políticas públicas que têm por finalidade promover a igualdade substancial entre grupos sociais que se encontram em situação de desequilíbrio em relação às oportunidades de ascensão econômica, política e educacional. A colonização europeia e a política integracionista, no caso do índio, são as razões históricas e sociais que fundamentam a necessidade da criação de políticas de inclusão.

Segundo Flávia Piovesan ${ }^{27}$, as ações afirmativas devem ser utilizadas "para aliviar e remediar as condições resultantes de um passado de discriminação (...) assegurar a diversidade e a pluralidade social. Constituem medidas concretas que viabilizam o direito à igualdade, com a crença de que a igualdade deve moldar-se no respeito à diferença e à diversidade. Por meio delas, transita-se da igualdade formal para a igualdade material e substantiva."

Tais ações permitem reduzir e eliminar fatores que perpetuam a discriminação, devendo ser concebidas como uma compensação em face de um passado de discriminação e, sobretudo, como um instrumento voltado à transformação social.

${ }^{25}$ Disponível em: <http://www.planalto.gov.br/ccivil_03/decreto/1950-1969/D65810. html>. Acesso em: 05 maio 2020.

${ }^{26}$ Para o conceito de raça, interessante o julgamento do HC/RS nº 82424-2 pelo Supremo Tribunal Federal.

27 Disponível em: <https://www.scielo.br/scielo.php?script=sci_arttext\&pi$\mathrm{d}=$ S0100-157420050001000 04\& lng=pt\&tlng=pt>. Artigo: Ações Afirmativas da perspectiva dos direitos humanos. Acesso em: 05 maio 2020. 
A Convenção também traz o dever de os Estados reconhecerem as diversidades étnico-raciais em suas Constituições, elevando-as como valores fundamentais de nações pluriétnicas e multirraciais, a exemplo do que ocorre em países como Bolívia, Colômbia, Peru, Venezuela e Equador.

Assim, da compreensão de que Estado não pode permanecer indiferente e omisso face dessas desigualdades, as ações afirmativas, dentre elas as cotas, auxiliam as minorias a ter acesso a direitos e bens fundamentais.

A política partidária é um campo historicamente dominado por homens e encontra-se estruturada a possibilitar a reprodução da hierarquia institucionalizada reservada ao gênero masculino. As mulheres, assim como os índios, transgêneros e negros, são discriminados.

As cotas eleitorais desempenham uma importante função em matéria de ampliar a participação política de grupos menos favorecidos. As cotas de gênero foram criadas com o objetivo de garantir a participação feminina na disputa eleitoral. A Lei das Eleições (Lei 9.505/1997) previu no artigo $10, \int 3^{\circ}$ que os partidos políticos devem respeitar o percentual mínimo de 30\% (trinta por cento) e o máximo de 70\% (setenta por cento) para candidaturas de cada sexo.

Com isso, no ato do pedido de registro de candidaturas à Justiça Eleitoral, cada partido deve indicar o mínimo de 30\% de mulheres filiadas para concorrer nas eleições proporcionais da Câmara dos Deputados, das Câmaras Municipais e das Assembleias Legislativas. A Emenda Constitucional nº 97/2017 vedou, a partir das eleições de 2020, a celebração de coligações nas eleições proporcionais, o que amplia ainda mais a participação feminina na política.

As cotas eleitorais podem ser de dois tipos: a primeira ocorre quando da apresentação dos candidatos à Justiça Eleitoral pelo partido (a exemplo da cota de gênero); e a segunda, ocorre quando da distribuição dos assentos parlamentares. As cotas podem incidir em qualquer das fases, tanto sobre as candidaturas, quanto diretamente sobre o parlamento, via reserva de assentos.

Nesse contexto, o Partido dos Trabalhadores (PT) apresentou proposta de emenda à Constituição - PEC 320/2013 - pretendendo nova redação ao artigo 45 da Constituição da República ${ }^{28}$, criando 04 (quatro) vagas especiais de deputado federal para as comunidades indígenas.

\footnotetext{
${ }^{28}$ Art. 45. A Câmara dos Deputados compõe-se de representantes do povo, eleitos, pelo sistema proporcional, em cada Estado, em cada Território e no Distrito Federal.
} 
As vagas destinadas aos indígenas seriam adicionadas às atuais 513 (quinhentas e treze) e os deputados viriam de eleições específicas nas reservas. $\mathrm{O}$ voto indígena abrangeria todos os eleitores que tivessem domicílio eleitoral na própria comunidade e previa, no momento do alistamento eleitoral, a opção por votar em eleições gerais ou nas específicas de representação especial destinada aos povos indígenas.

A proposta de emenda constitucional foi arquivada na data de 05 de agosto de 2014, antes de chegar ao plenário, ao argumento de inconstitucionalidade, perante a Comissão de Constituição e Justiça e de Cidadania - CCJ da Câmara dos Deputados.

A falta de representação indígena não é problema inerente apenas à sociedade brasileira, ou restrita a ela. O tema é de grande repercussão na América Latina desde o início da colonização europeia.

Diferentemente do Brasil, a Constituição de alguns países da América do Sul estipula número determinado de indígenas no corpo legislativo. México, Chile, Venezuela e Colômbia possuem norma específica reservando assentos indígenas no parlamento, por meio das cotas eleitorais. A Bolívia, por outro lado, também deve ser mencionada pelo fato de haver, em sua Constituição, inovado no reconhecimento do direito dos povos indígenas.

\section{Bolívia $^{29}$}

A Bolívia, apesar de não possuir cotas de representação política para os índios, foi o primeiro país a eleger um presidente indígena: Evo Morales.

A Constituição boliviana de 2009 cria um Estado plurinacional garantidor da autonomia indígena e do seu direito à terra, incluindo efetivamente os índios no processo de construção política, trazendo maior representatividade a essas populações.

$\int 1^{\circ} \mathrm{O}$ número total de deputados, bem como a representação por Estado e pelo Distrito Federal, será estabelecido por lei complementar, proporcionalmente à população, procedendo-se aos ajustes necessários, no ano anterior às eleições, para que nenhuma daquelas unidades da Federação tenha menos de oito ou mais de setenta deputados.

$\int 2^{\circ}$ Cada Território elegerá quatro deputados.

${ }^{29}$ Disponível em: <https://www.oas.org/dil/esp/Constitucion_Bolivia.pdf>. Acesso em: 05 maio 2020. 
É o país com a maior população indígena entre as nações latino-americanas, de acordo com o relatório da Organização das Nações Unidas (ONU), a Bolívia possui aproximadamente 12.000.000 (doze milhões) de habitantes dos quais $62,2 \%$ (sessenta e dois vírgula dois por cento) identificam-se como indígenas. Não são minoria.

Os indígenas bolivianos possuem legislação específica, que funciona como uma espécie de Constituição, e define a forma de eleição das autoridades; modelo de funcionamento, funções, objetivos governamentais, bem como a participação dos índios na comunidade, coexistindo com a Carta boliviana, e não altera, tampouco confronta normas nacionais e regionais de coordenação com entidades estatais.

A polícia, as Forças Armadas, instituições estatais e normas instauradas pelos três poderes da Bolívia não são afetados pela legislação indígena. Porém, é assegurada autonomia indígena para promoção de seus próprios critérios de organização interna, de gestão de recursos econômicos e de promoção de seu desenvolvimento.

\section{México $^{30}$}

O México possui 126.000.000 (cento e vinte e seis milhões) de habitantes. Segundo estatísticas oficiais, 25.000 .000 (vinte e cinco milhões) de mexicanos se reconhecem como indígenas, e, graças a uma ação afirmativa aprovada pela autoridade estatal local, o Instituto Nacional Eleitoral, foram criadas no fim de 2017, cotas eleitorais garantindo o número mínimo de 13 (treze) deputados federais indígenas, representando 2,6\% (dois vírgula seis por cento) dos 500 (quinhentos) assentos da Câmara.

A medida não foi unânime, sendo duramente criticada por alguns partidos sob o argumento de ferir os princípios de autorregulação e autodeterminação do Poder Legislativo. Porém, o Tribunal Eleitoral Mexicano, o rejeitou por considerar a necessidade de representação das comunidades indígenas, assim como, o compromisso e a dívida histórica com a população indígena.

Posteriormente, em 06 de junho de 2019 foi incluído o artigo 2ª A, VIII na Constituição Mexicana garantindo a eleição de representantes indígenas para as prefeituras, observada a regra de paridade de gênero.

\footnotetext{
${ }^{30}$ Disponível em: < http://www.diputados.gob.mx/LeyesBiblio/pdf_mov/Constitucion_ Politica.pdf>. Acesso em: 05 maio 2020.
} 
Com a nova norma, os partidos e as coalizões terão obrigatoriamente de possuir candidatos indígenas para garantir a representação eleitoral mínima indígena.

\section{Chile $^{31}$}

O Chile possui aproximadamente 19.000.000 (dezenove milhões) de habitantes, dos quais 800.000 (oitocentos mil) são índios. Como resposta aos apelos populares, o parlamento chileno aprovou recentemente cotas indígenas para as cadeiras no Legislativo.

\section{Venezuela ${ }^{32}$}

De acordo com o artigo 186 da Constituição de 1999, a Assembleia Venezuelana é composta por 167 (cento e sessenta e sete) deputados eleitos por voto universal, direto, pessoal e secreto em um sistema de representação proporcional. Desses, 03 (três) assentos são reservados para representantes dos povos indígenas, eleitos separadamente por todos os cidadãos, não apenas por pessoas de origem indígena.

A Venezuela possui cerca de 40.000 .000 (quarenta milhões) de habitantes e 650.000 (seiscentos e cinquenta mil) pessoas identificam-se como indígenas.

\section{Colômbia ${ }^{33}$}

A Colômbia possui pouco mais de 49.000 .000 (quarenta e nove milhões) de habitantes e desses, 400.000 (quatrocentos mil) identificam-se como índios.

O Senado colombiano é composto de 102 (cento e dois) senadores e o artigo 171 da Constituição de 1991 prevê 02 (duas) vagas para representantes de comunidades indígenas em circunscrição nacional especial. Os representantes de comunidades indígenas devem ter exercido algum cargo

31 Disponível em: <https://www.senado.cl/pueblos-originarios-plantean-paridad-y-proponen-entre-20-y-24- escanos/senado/2020-01-17/093808.html>. Acesso em: 05 maio 2020 .

32 Disponível em: <https://www.oas.org/dil/esp/constitucion_venezuela.pdf>. Acesso em: 05 maio 2020

${ }^{33}$ Disponível em: < https://www.corteconstitucional.gov.co/inicio/Constitucion\% 20politica $\% 20$ de $\% 20$ Colombia.pdf>. Acesso em: 05 maio 2020. 
de autoridade em suas comunidades ou terem sido líderes de organizações indígenas. Exige-se, ainda, nacionalidade colombiana nata e idade maior de 30 (trinta) anos.

\section{Considerações finais}

O principal motivo que mantém os povos indígenas à margem do cenário político é o preconceito racial e a ausência de oportunidade para o exercício dos direitos políticos em condições que privilegiem as diferenças culturais e tradicionais dessa comunidade.

A invisibilidade dos índios pode ser atenuada por medidas de inclusão que variam desde a forma como a norma eleitoral é interpretada até a adoção de ações afirmativas, que permitem reduzir fatores de discriminação. Por vezes, a interpretação da lei pode criar obrigações desnecessárias ao exercício do direito de sufrágio, inviabilizando o exercício da cidadania. Por outro lado, as políticas públicas, a exemplo das cotas, funcionam como um mecanismo de correção das desigualdades sociais e econômicas que impedem a ascensão de determinados grupos vulneráveis.

A participação política e a autodeterminação dos povos indígenas são duas faces da mesma moeda, que asseguram o reconhecimento da diversidade cultural e garantem a autonomia pública dos povos indígenas. A Constituição Federal cria um sistema de proteção especial ao reconhecer a organização social, os costumes, as línguas, crenças e tradições, além dos direitos originários sobre as terras que tradicionalmente ocupam.

Os povos indígenas são autônomos e livres para participar do processo político, escolher seus representantes, integrar instituições representativas, ocupar cargos públicos e políticos, fazer parte de movimentos sociais, conforme suas tradições e cultura.

Nos últimos anos, alguns governos sul-americanos reconheceram o caráter multiétnico e pluricultural de suas sociedades nacionais e a necessidade de respeito para o alcance da estabilidade política e progresso social. O Brasil, porém, em sentido contrário, entrega aos povos indígenas os mesmos parâmetros para a escolha de representantes dos demais cidadãos, por isso as comunidades indígenas podem encontrar dificuldades para inserirem-se no sistema partidário e representativo da política brasileira.

Ao longo do artigo, ficam claras duas visões do processo político: a incipiente inserção da comunidade indígena no processo eleitoral e 
a ausência de políticas públicas para modificar esse cenário. Esse quadro decorreu, em boa parte, da política de assimilação, da discriminação e da constante luta da comunidade indígena para garantir o respeito a sua cultura. A intepretação e o alcance das normas eleitorais também são fatores importantes que contribuem para a não inclusão dos índios no processo eleitoral.

A criação de cotas eleitorais pode ser um importante instrumento de transformação da realidade indígena, ampliando a participação e a representativa política. Por outro lado, uma maior atenção da Justiça Eleitoral na tentativa de alinhar as normas eleitorais ao espírito da Constituição, em respeito à diversidade cultural dos povos étnicos, é também uma necessidade que não pode ser ignorada.

\section{Referências}

ANJOS FILHO, Rogério Nunes dos. O direito à autodeterminação dos povos indígenas: entre a secessão e o autogoverno. In: ANJOS FILHO, Rogério Nunes dos (Ed.). Direitos Humanos e Direitos Fundamentais: diálogos contemporâneos. Salvador: JusPodivm, 2013.

BARROSO, Luís Roberto. Aqui, lá e em todo lugar: a dignidade humana no direito contemporâneo e no discurso transnacional. Trad. Humberto Laport de Mello. Revista dos Tribunais, São Paulo, v. 101, n. 919, p. 127-196, maio 2012.

\section{CAGGIANO, Mônica Herman S. Sistemas eleitorais x representação} política. São Paulo, 1987. p. 72.

KAYSER, Hartmut-Emanuel. Os direitos dos povos indígenas do Brasil: desenvolvimento histórico e estágio atual. Porto Alegre: S. A. Fabris, 2010. LUCIANO. Gersem dos Santos: O Índio Brasileiro: o que você precisa saber sobre os povos indígenas no Brasil de hoje. Brasília: MEC/SECAD; LACED/Museu Nacional, 2006. 233p. (Coleção Educação Para Todos. Série Vias dos Saberes n. 1). Disponível em: <http://www. educadores.diaadia. pr. gov.br/arquivos/File/ pdf/indio_brasileiro.pdf > . Acesso em: 05 maio 2020. MENDES, Antônio Carlos. Introdução à Teoria das Inelegibilidades. São Paulo, Malheiros, 1994.

HABERMAS, Jürgen, Between Facts and Norms: Contributions to a Discourse Theory of Law and Democracy, 1996. 
SAMPAIO, Nelson de Sousa. O Poder de Reforma Constitucional. Bahia: Livraria Progresso Editora, 1954.

SANTANA, Carolina R. Direitos territoriais indígenas: o STF contra a Constituição. In: ALCÂNTARA, Gustavo Kenner; MAIA, Luciano Maris; TINÔCO, Lívia N. (Org.). Índios, direitos originários e territorialidade. Brasília: Editora ANPR, 2018.

Carolina Canhassi Pereira - Advogada. Mestranda em Direito Constitucional na PUC/SP. Pós-graduada em Direito Eleitoral e Processual Eleitoral pela EJEP do TRE/SP. Graduada pela PUC/SP.

Antônio Raimundo Barros de Carvalho Júnior - Servidor público. Mestrando em Direito do Estado e Filosofia do Direito. Pós-graduado em Direito Processual Civil pela FMU. Graduado pela Universidade Nilton Lins (AM). 